\section{Teaching the Core Concepts of Physiology: What, Why, and How}

\author{
Review of: The Core Concepts of Physiology: A New Paradigm for Teaching \\ Physiology, by Joel Michael, Wvilliam Cliff, Jenny McFarland, Harold Modell, \\ and Ann Wright; 2017; 153 pp.; Springer (New York); ISBN 978-1-4939-6907-4 \\ (hardcover and eBook editions)
}

Reviewed by Gregory J. Crowther, ${ }^{*}$ Life Sciences Department, Everett Community College, Everett, WA 98201

A s someone who mostly teaches undergraduate anatomy and physiology, I was excited to check out this new book by Michael et al., which seems to have been written especially for undergraduate instructors like me. According to its back cover, Core Concepts "offers physiology teachers a new approach to teaching their subject that will lead to increased student understanding and retention of the most important ideas." In particular, the authors argue that we can teach physiology better by infusing our curricula with specific core concepts developed and refined in faculty workshops and surveys. Core Concepts has two primary aims: defining and unpacking the core concepts (Part II: Chapters 3-7), and discussing the integration of these core concepts into the teaching of physiology (Part III: Chapters 8-12).

In my opinion, Core Concepts is a spectacular success in terms of presenting provocative, contemplation-worthy ideas based on the authors' education research and teaching experience. The page margins of my copy are heavily annotated with comments ("Important," "Interesting," "YES!," "Really?!?," "I disagree," etc.) indicating that, as a reader, I felt engaged and challenged throughout the 14 concise chapters. Core Concepts may even be interesting to nonphysiologists wishing to compare the pedagogical frameworks of physiology with those of their own subdisciplines.

The book's laser-like focus on the titular core concepts is arguably a great strength, both in maximizing clarity and in allowing readers to read the entire thing during, say, a 1-week vacation. However, a book this short will inevitably disappoint people seeking more coverage of topics that were not emphasized. Here, the people most likely to be disappointed may be those at the "extremes" of the biology education community. At one end, those who want a comprehensive review of all related research will not find it here; the book cites only 88 sources ( 29 of which are the authors' own work), and highly relevant topics such as concept inventories and learning progressions are discussed only in passing. At the other end, those who are uninterested in the research findings and simply want classroom-ready resources (e.g., ready-to-use figures, worksheets, and test questions) will find few of those. I suspect that most CBE-Life Sciences Education (LSE) readers lie somewhere between these extremes, and thus would be satisfied with the book's research-to-resource ratio. Still, some may rightly wonder why the authors have so little to say about anatomy, given that structure (anatomy) and function (physiology) go hand in hand and are often taught together as a single course. Leaders of the Human Anatomy \& Physiology Society are addressing this gap by adapting Michael and colleagues' core concepts for the many courses that give equal weight to anatomy and physiology (Hull et al., 2017).

The initial premise of Core Concepts is a strong one, too obvious to dispute yet too important to ignore. So much physiology content is now known that students can only learn a tiny fraction of it in any given course, Michael and coauthors argue; therefore, instructors should direct students' attention to a few unifying core concepts (or "big
CBE Life Sci Educ December 1, 2017 16:fe7 DOI:10.1187/cbe-17-09-0198

*Address correspondence to: Gregory J. Crowther (gcrowther aeverettcc.edu). (C) 2017 G. J. Crowther. CBE-Life Sciences Education (c) 2017 The American Society for Cell Biology. This article is distributed by The American Society for Cell Biology under license from the author(s). It is available to the public under an Attribution-Noncommercial-Share Alike 3.0 Unported Creative Commons License (http:// creativecommons.org/licenses/by-nc-sa/3.0). "ASCB ${ }^{\circledR}$," "The American Society for Cell Biology ${ }^{\circledR}$," and "Molecular Biology of the Cell ${ }^{\circledR}$ " are registered trademarks of The American Society for Cell Biology. 
ideas"). The authors thus aim to discern what those core concepts should be and how to emphasize them in physiology curricula.

The work that would become the core of Core Concepts began a decade ago, when instructors gathered at National Science Foundation-sponsored meetings on Conceptual Assessment in Biology (CAB) to define the "big ideas of biology." Faculty working groups then adapted these into 15 physiologyspecific core concepts, as follows: evolution; homeostasis; causality; energy; structure/function; cell theory; levels of organization; cell-cell communication; cell membrane; flow down gradients; genes to proteins; interdependence; mass balance; physics/chemistry; and scientific reasoning.

The initial goal of these faculty working groups was to create a concept inventory (D'Avanzo, 2008) for assessing students' understanding of these concepts. This goal initially proved elusive, though, as the authors explain (p. 35),

It quickly became obvious to us that it was impossible to assess student's [sic] understanding of a complete core concept using multiple-choice questions. The complexity of each core concept was too great to be captured in a realistic number of multiple-choice questions. Thus, we concluded that we needed to break a core concept into its constituent parts and then determine whether students understood the smaller, constituent concepts.

In this context, the authors devote Chapters 5-7 to the "unpacking" (i.e., breaking into constituent parts, or subconcepts) of three of the most important core concepts: homeostasis, flow down gradients, and cell-cell communication. As an example, the concept of flow down gradients is unpacked as shown in Table 1 . In the authors' estimation, this core concept encompasses five subconcepts (F1 to F5), most of which can themselves be further subdivided. In all, the unpacked conceptual framework for flow down gradients includes 20 statements that center around 10 vocabulary words (listed in Table 2 ) identified as critical by Michael and colleagues. Similarly detailed frameworks are presented for homeostasis and cell-cell communication (Table 2).

I feel slightly conflicted about all of this unpacking. On the one hand, it is very satisfying and useful to see each concept dissected so precisely and thoroughly. In reviewing Table 1, for example, I marvel at how much important physiology underlies the seemingly simple concept of flow down gradients. The authors have done the physiology education community a great service by elaborating the components of these core concepts, which we instructors can examine to check and refresh our understanding.

Helping students achieve a similar understanding is another matter, though. The sheer number of statements and definitions included in the unpacked concepts (Table 2) is enormous, so they must somehow be filtered for students. But how might this be done? For example, should a class approach a core concept from the bottom up (i.e., by starting with the component subconcepts and building the larger core concept from those) or from the top down (i.e., by first tackling the overall core concept and then dissecting it into subconcepts)? Vocabulary-wise, should a class first define some (or all?) of the key terms and then explore how they interact in the context of a core concept, or should one start with the core concept and then acquire just-in-time definitions of terms as needed?

Core Concepts does not directly handle such unpacking-related questions. For instance, Chapter 9 ("Teaching Physiology Using the New Paradigm: Three Examples") shows how multiple core concepts can be interwoven into the teaching of the

\section{TABLE 1. Unpacking the core concept of flow down gradients ${ }^{a}$}

F1. Flow is the movement of "substances" from one point in the system to another point in the system.

F1.1 Molecules and ions can diffuse through a solution.

F1.2 Fluid (blood, chyme) and gases are transported through tubes.

F1.3 Heat can move through objects.

F2. Flow occurs because of the existence of an energy gradient between two points.

F2.1 Differences in concentration (concentration gradients) cause molecules and ions in solution to move down a gradient from high to low concentration.

F2.2 Differences in electrical potential (potential gradient) cause ions in solution to move from high to low electrical potential.

F2.3 Differences in pressure (pressure gradient) between two points in a system cause substances to move toward a region of lower temperature.

F2.4 Differences in temperature (temperature gradient) between two points cause heat to flow from the hotter to the cooler location.

F3. The magnitude of the flow is a direct function of the magnitude of the energy gradient that is present-the larger the gradient, the greater the flow.

F4. More than one gradient can determine the magnitude and direction of flow.

F4.1 Osmotic (concentration gradient for water) and hydrostatic pressure gradients together determine flow across the capillary wall.

F4.2 Concentration gradients and electrical gradients determine ion flow through channels in cell membranes.

F5. There is resistance or opposition to flow in all systems.

F5.1 Resistance and flow are reciprocally related — the greater the resistance, the smaller the flow.

F5.2 The resistance to flow is determined by the physical properties of the system.

F5.3 Some resistances can be varied and can be actively (physiologically) controlled.

F5.3.1 Ion channels in a membrane can open and close, changing resistance (decreasing and increasing, respectively).

F5.3.2 Arterioles and bronchioles can constrict (increasing resistance) and dilate (decreasing resistance).

F5.3.3 Pilo-erection can increase the resistance to heat flow in many animals.

${ }^{a}$ This is Table 6.1 in Michael et al. (2017). 
TABLE 2. Overview of unpacking of core concepts by Michael et al. ${ }^{\mathrm{a}}$

\begin{tabular}{lcc}
\hline Chapter: core concept & Statements in conceptual framework & Terms defined in conceptual framework \\
\hline 5: Homeostasis & 30 & $\begin{array}{c}16 \text { (control center, controller, effector, error detector, error signal, } \\
\text { external environment, integrator, internal environment, homeostasis, } \\
\text { negative feedback, nonregulated variable, perturbation, regulated } \\
\text { variable, response, sensor, set point) }\end{array}$ \\
$\begin{array}{l}\text { 6: Flow down gradients } \\
\text { 7: Cell-cell communication }\end{array}$ & 51 & $\begin{array}{c}10 \text { (bulk flow, concentration, diffusion, electrical potential, energy, flow, } \\
\text { gradient, hydrostatic pressure, osmosis, resistance) }\end{array}$ \\
& $\begin{array}{l}13 \text { (amplification, biological response, cell function, enzyme, messenger, } \\
\text { receptor, second messenger, signal transduction, target, termination, } \\
\text { transcription, translation, transport) }\end{array}$ \\
\hline
\end{tabular}

${ }^{a}$ Compiled from Tables 5.1, 5.2, 6.1, 6.2, 7.1, and 7.2 of Michael et al. (2017).

regulation of blood pressure, respiratory generation of tidal volumes, and the hypothalamic-pituitary-adrenal axis, yet there is no explicit advice on whether or how to handle the messy unpacked details of each core concept. This issue-how the unpacking might inform one's interactions with students-is eventually partially addressed in Chapter 12 ("Core Concepts and the Physiology Curriculum"), in which the authors try to organize the subconcepts into learning progressions (Duschl et al., 2011). Here, the authors propose that some subconcepts can and should be introduced earlier in the curriculum than others. Their well-intentioned efforts come across as tentative, though, perhaps because (as they claim) the limited research on learning progressions does not yet justify detailed recommendations. However, even in the absence of relevant high-quality research, I would have appreciated more specific ideas on how to use the unpacking (as opposed to the core concepts themselves) to teach better.

Chapters 9 and 12 are part of the book's third section- "Implementing the New Paradigm for Teaching Physiology"which also includes chapters on designing learning resources (Chapter 10) and assessing students' learning (Chapter 11). These chapters contain plenty of sensible advice; for example, the authors insist that we use consistent terminology every time we return to a given core concept so that students recognize it as the same concept that was covered before. However, I also found several nits to pick. The discussion of assessment emphasizes multiple-choice questions, which makes sense in terms of grading efficiency, but I claim that there is no substitute for short-answer questions in forcing students to articulate their reasoning. Moreover, the examples of Homeostasis Concept Inventory questions (in Table 11.1) seemed unduly focused on what I consider a minor semantic issue (i.e., whether a homeostatic mechanism should be considered "active" all the time or only when a regulated variable diverges from its set point).

The authors also assume too readily that most or all current textbooks and instructors present students only with lists of facts rather than unifying frameworks such as the core concepts.
They write, rather dismissively, "Textbooks are a source for the 'facts' that represent our current understanding of physiology. To the extent that your learning objectives (see Chapter 9) include some set of these facts, textbooks can serve to make these available to your students" (p. 117). However, Erin Amerman's (2016) outstanding new human anatomy and physiology textbook (which, despite its 2016 copyright date, has been available since January 2015) has already anticipated and incorporated many of their suggestions, such as using icons to flag recurring core concepts. Likewise, there are hints of condescension in passages such as, "Assessing understanding of the core concepts usually requires writing new types of questions with important properties; the usual exam questions that you have employed in the past will not generally be suitable" (p. 125). The implication is that, up to now, few if any instructors have bothered to teach and assess core concepts, though most of my current and past colleagues believe they are doing just that.

Despite these and other caveats, I recommend the book highly. The fact that it provoked varying reactions in me is mostly to its credit and indicates its potential for sparking lively discussions among instructors who wish to put their own teaching under the proverbial microscope.

\section{REFERENCES}

Amerman, E. (2016). Human anatomy \& physiology. Boston: Pearson.

D'Avanzo, C. (2008). Biology concept inventories: Overview, status, and next steps. BioScience, 58(11), 1079-1085.

Duschl, R., Maeng, S., \& Sezen, A. (2011). Learning progressions and teaching sequences: A review and analysis. Studies of Science Education, 47(2), $123-182$.

Hull, K., Jensen, M., Gerrits, R., \& Ross, K. T. (2017). Core concepts for anatomy and physiology: A paradigm shift in course and curriculum design. HAPS Educator, 21(2), 73-79.

Michael, J., Cliff, W., McFarland, J., Modell, H., \& Wright, A. (2017). The core concepts of physiology: A new paradigm for teaching physiology. New York: Springer. 